\title{
Fracionamento e Cinética de Degradação In Vitro dos Compostos Nitrogenados da Extrusa de Bovinos a Pasto ${ }^{1}$
}

\section{Ricardo Augusto Mendonça Vieira², José Carlos Pereira ${ }^{3}$, Pedro Antonio Muniz Malafaia ${ }^{4}$, Augusto César de Queiroz ${ }^{3}$, André Luigi Gonçalves ${ }^{5}$}

\begin{abstract}
RESUMO - O objetivo básico do presente estudo foi a determinação do fracionamento dos compostos nitrogenados presentes na extrusa de bovinos mantidos em pastagem natural, na região da Zona da Mata, MG. Foram empregados quatro novilhos fistulados no esôfago, em dois períodos experimentais durante a estação chuvosa (EC) do ano de 1996, e três destes animais em dois períodos experimentais durante a estação seca (ES) do mesmo ano. Para determinação do fracionamento dos compostos nitrogenados (frações A, $\mathrm{B}_{1}, \mathrm{~B}_{2}, \mathrm{~B}_{3}$ e $\mathrm{C}$ ), foram calculados os teores em proteína bruta ( $\left.\mathrm{PB}\right)$, nitrogênio não-protéico (NNP), nitrogênio insolúvel em tampão borato-fosfato, nitrogênio insolúvel em detergente neutro e insolúvel em detergente ácido. Os perfis de degradação in vitro das frações protéicas foram obtidos ao incubar as amostras de extrusa com proteases originárias do Streptomyces griseus. Com estas técnicas, foi possível detectar reduções no teor de $\mathrm{PB}$ e no percentual (\% da PB) da fração $\mathrm{B}_{3}$ e aumentos nos percentuais das frações $\mathrm{A}$, $\mathrm{B}_{1}$ e $\mathrm{C}$ da EC para a ES; não houve alteração no percentual da fração $B_{2}$ em função da estação. As taxas de degradação das frações $B_{2}$ e $B_{3}$ foram extremamente variáveis: suas estimativas médias foram de $2,427 \mathrm{~h}^{-1}$ e 0,057 , respectivamente, durante a estação chuvosa, e 2,149 e $0,034 \mathrm{~h}^{1}$, durante a estação seca.
\end{abstract}

Palavras-chave: compostos nitrogenados, pastos tropicais, ruminantes

\section{Fractionation and In Vitro Degradation Kinetics of Extrusa Nitrogenous Compounds from Grazing Cattle}

\begin{abstract}
The objective of the present study was to determinate the nitrogenous compounds fractions present in the extrusa of grazing cattle maintained in a natural grassland in the Zona da Mata region, MG. The samples were obtained by using four esophageal fistulated steers in two experimental periods during the rainy season of 1996, and three of these animals were used to take samples in two experimental periods during the dry season of the same year. In order to obtain the nitrogen fractionation (fractions $\mathrm{A}, \mathrm{B}_{1}, \mathrm{~B}_{2}, \mathrm{~B}_{3}$ e C), the crude protein (CP), non-protein nitrogen (NPN), borate-phosphate buffer insoluble nitrogen, and neutral detergent and acid detergent insoluble nitrogen were determined. The in vitro degradation profiles of the protein fractions were obtained by incubating the pasture samples with Streptomyces griseus proteases. With these techniques it was possible to detect reductions in the $\mathrm{CP}$ content and in the percentage $(\% \mathrm{CP})$ of $\mathrm{B}_{3}$ fraction and increases in the percentages of the $\mathrm{A}, \mathrm{B}_{1}$ and $\mathrm{C}$ fractions from $\mathrm{EC}$ to $\mathrm{ES}$; no differences were found for the percentage of the fraction $\mathrm{B}_{2}$ between seasons. The degradation rates of fractions $\mathrm{B}_{2}$ and $\mathrm{B}_{3}$ were extremely variable: its average estimates were 2.427 and $0.057 \mathrm{~h}^{-1}$, respectively, during the rainy season, and 2.149 and $0.034 \mathrm{~h}^{-1}$, during the dry season.
\end{abstract}

Key Words: nitrogenous compounds, tropical pastures, ruminants

\section{Introdução}

O rebanho bovino no Brasil é basicamente criado sob condições nas quais as pastagens constituem importante fonte de nutrientes. Portanto, é necessária a busca de melhor entendimento dos mecanismos que governam a digestão ruminal desses compostos, para o aproveitamento adequado das pastagens pelos animais.

O baixo valor nutritivo das forrageiras que com- põem os pastos tropicais é a principal causa da menor produtividade do rebanho bovino, principalmente quando se trata de animais com elevada demanda por nutrientes (MINSON et al., 1976; VAN SOEST, 1994). O estudo do valor nutritivo do pasto torna possível identificar as principais causas limitantes do nível de produção, o que permite deduzir estratégias de manejo que resultem em incremento na produção animal. A utilização estratégica da suplementação

\footnotetext{
${ }^{1}$ Parte da Tese de Doutorado do primeiro autor, financiada pelo CNPq.

2 Professor Adjunto, UEG, Anápolis, GO; Pesquisador, NASB/CCA/IMEP, Caixa Postal 21, cep: 75180-000, Silvânia, GO.

3 Prof. Titular, DZO/UFV, Viçosa - MG.

4 Prof. Adjunto, DNAP/IZ/UFRRJ, Seropédica RJ.

${ }^{5}$ Pesquisador, convênio PROCABRA/DZO/UFV, Viçosa, MG.
} 
energética, protéica e, ou, mineral pode ser empregada como forma de se incrementar a produtividade animal sob condições de pastejo (MINSON et al., 1976; LENG, 1993).

A natureza dos compostos nitrogenados, presentes nos alimentos comumente empregados na alimentação dos ruminantes, afeta a eficiência com a qual os microrganismos do rúmen utilizam o nitrogênio $(\mathrm{N})$ dietético. Logo, a eficiência de utilização do $\mathrm{N}$ pelo hospedeiro é, de certa forma, também afetada.

O valor protéico dos alimentos pode ser conhecido por meio da determinação da quantidade de ácidos aminados absorvidos no intestino delgado; tais compostos são oriundos da proteína dietética que escapa à degradação ruminal e do total do $\mathrm{N}$ disponível que é transformado em proteína microbiana em nível de rúmen. A medição da digestão ruminal do N, utilizando-se animais fistulados, não é simples. Por isso, métodos alternativos para a sua estimativa têm sido desenvolvidos, nos quais são empregados sistemas microbiológicos, químicos e, ou, enzimáticos (NOCEK, 1988). Nos sistemas de avaliação de alimentos, recorre-se a tais métodos para predição da disponibilidade protéica e energética dos alimentos (SNIFFEN et al., 1992; AGRICULTURAL AND FOOD RESEARCH COUNCIL - AFRC, 1993; NATIONAL RESEARCH COUNCIL - NRC, 1996).

Os procedimentos para determinação da solubilidade da proteína têm sido recomendados como rotina laboratorial prévia aos estudos de degradabilidade ruminal da proteína bruta (MADSEN e HVELPLUND, 1994); no entanto, a extração do nitrogênio por meio de tampões não permite discriminar a fração constituída de nitrogênio não-protéico (NNP) daquela de natureza protéica (VAN SOEST, 1994). Além disso, os relatos na literatura versam sobre a existência de associação positiva entre a degradabilidade da proteína bruta e sua solubilidade, porém tal observação empírica carece de entendimento mais detalhado das características cinéticas relativas às diferentes fontes protéicas dos alimentos (VAN SOEST, 1994; BRODERICK, 1995). A interpretação cinética dos dados de degradação da proteína deve basear-se na distinção entre o nitrogênio solúvel após o tratamento com agentes químicos, que promovem a precipitação das formas protéicas, e o nitrogênio insolúvel residual após o tratamento com estes compostos; o último representa as frações verdadeiramente protéicas, potencialmente degradáveis $\left(\mathrm{B}_{1}, \mathrm{~B}_{2}\right.$ e $\left.\mathrm{B}_{3}\right)$ e indegradável $(\mathrm{C})$, dos alimentos (SNIFFEN et al., 1992; VAN SOEST, 1994; LICITRA et al., 1996).
O CNCPS - The Cornell Net Carbohydrate and Protein System (FOX et al., 1992; RUSSELL et al., 1992; SNIFFEN et al., 1992; e O'CONNOR et al. 1993), ou sistema Cornell, foi desenvolvido basicamente com o objetivo de avaliar dietas completas, visando minimizar as perdas de nutrientes e buscar a maximização da eficiência de crescimento dos microrganismos ruminais (RUSSELL et al., 1992). As estimativas dos parâmetros cinéticos empregados neste sistema foram obtidas para os alimentos comumente usados nos Estados Unidos. Sua aplicação no Brasil só poderá ser realizada, eficientemente, se forem conduzidos ensaios para obtenção das estimativas de tais parâmetros, principalmente no que diz respeito às forrageiras tropicais.

O objetivo básico do presente estudo foi a caracterização dos compostos nitrogenados em amostras de extrusa de bovinos a pasto, no que diz respeito às frações protéicas verdadeiras, potencialmente degradáveis, à fração protéica indegradável, à fração de NNP e à obtenção das taxas de degradação das frações protéicas potencialmente degradáveis.

\section{Material e Métodos}

As amostras representativas de uma pastagem natural, situada na Zona da Mata, Estado de Minas Gerais, foram obtidas de animais fistulados no esôfago, durante as estações chuvosa (EC) e seca (ES) do ano de 1996. Foram usados quatro animais durante dois períodos de coleta na EC (22/1 a 27/1 e 9/02 a 14/2) e três animais durante dois períodos de coleta na ES (7/8 a 12/8 e 28/8 a 2/9). Os animais foram mantidos durante os meses de janeiro e fevereiro de 1996 e de julho a meados de setembro do mesmo ano na área experimental. Esta, por sua vez, media aproximadamente 9 ha, com topografia bastante acidentada e uma seqüência de segmentos côncavo-convexo-topo, conforme designados por REZENDE et al. (1972), e era coberta pela vegetação característica da região: estrato arbóreo-arbustivo e estrato herbáceo, com diversas espécies de gramíneas, entre as quais têmse o capim-gordura (Melinis minutiflora), o capim-sapé (Imperata brasiliensis), o capim-jaraguá (Hyparrhenia rufa) e a grama-batatais (Paspalum sp.), coexistindo com leguminosas, em que se destacam o calopogônio (Calopogonium mucunoides) e o siratro (Macroptilium atropurpureum), ervas e arbustos; tais espécies e grupos de espécies, segundo DIOGO (1995), estão presentes em ordem decrescente de disponibilidade nessa área. 
882 Rev. bras. zootec.

Os animais eram presos em curral a partir das $19 \mathrm{~h}$ do dia anterior ao início do período de coletas, e soltos às $7 \mathrm{~h}$ do dia seguinte, com bolsas de lona (de fundo em tela plástica para o escorrimento do excesso de saliva) atadas ao pescoço, para coleta de amostras. Em geral, o período de pastejo necessário para coleta das amostras durava 30 minutos. Este procedimento era repetido a cada dia, durante os respectivos períodos de coleta. A área experimental foi dividida em três glebas, nas quais eram coletadas amostras, durante dois dias consecutivos. As amostras individuais de cada animal, assim que coletadas, eram conduzidas ao laboratório o mais rápido possível e secas em estufa ventilada (pré-aquecida) a $55^{\circ} \mathrm{C}$, por 72 horas. Em seguida, eram preparadas as amostras compostas por animal em cada período de coleta, tomando-se quantidades equivalentes em massa, tiradas das amostras individuais. As amostras compostas eram então moídas para atravessar peneira com malha de $1 \mathrm{~mm}$.

O fracionamento dos compostos nitrogenados contidos nas amostras de extrusa foi realizado a partir dos procedimentos padronizados, apresentados por LICITRA et al. (1996), e adaptados por MALAFAIA e VIEIRA (1997) e MALAFAIA et al. (1997).

As taxas de degradação das frações protéicas potencialmente degradáveis $\left(\mathrm{B}_{1}, \mathrm{~B}_{2}\right.$ e $\left.\mathrm{B}_{3}\right)$ foram obtidas in vitro, usando-se protease originária do Streptomyces griseus (número catalográfico P-5147, tipo XIV, Sigma Chemical Co., Saint Louis, Missouri, EUA). As amostras de extrusa (aproximadamente $0,5 \mathrm{~g}$ ) foram incubadas por 0,$25 ; 0,5 ; 1 ; 2 ; 4 ; 8 ; 12 ; 24$; 36; e 48 horas, em frascos erlenmeyers $(125 \mathrm{~mL})$, mantidos em incubadora com mesa de agitação orbital, à temperatura constante de $39^{\circ} \mathrm{C}$. Os procedimentos adotados para incubação das amostras em solução de protease seguiram a metodologia proposta por KRISHNAMOORTHY et al. (1983).

Uma vez obtidos os perfis de degradação da proteína bruta $(\mathrm{PB})$ das extrusas dos diferentes animais, em cada período, dentro de cada estação (EC e ES), procedeu-se à interpretação matemática para obtenção das estimativas das taxas de degradação, com base no modelo:

$$
R(t)=\sum_{i=1}^{3} B_{i} \cdot \exp \left(-c_{i} \cdot t\right)+C
$$

em que $R(t)$ corresponde ao resíduo de incubação no tempo $t(\mathrm{~h}) ; B_{i}(\%$ da PB), para $i=1,2$ e 3 , às frações de proteína potencialmente degradáveis; $c_{i}\left(\mathrm{~h}^{-1}\right)$, para $i=1,2$ e 3 , às taxas de degradação das frações $B_{i}$; e $C(\% \mathrm{~PB})$, à fração protéica indegradável, representada pela assíntota estabelecida no modelo, quando $t \rightarrow \infty$ (MALAFAIA e VIEIRA, 1997).

Pressupondo que os valores obtidos para a fração $C$ (\% da PB) representavam estimativas razoáveis para este mesmo parâmetro na equação (1), as taxas de degradação das frações $B_{i}$ foram obtidas após inspeção gráfica do logaritmo natural dos resíduos de incubação da proteína bruta, em função do tempo, para identificação dos diferentes intervalos em que os pontos não desviavam da linearidade. A identificação desses intervalos permitiu o ajuste dos dados a equações de regressão linear, cujos coeficientes de regressão correspondiam às taxas de degradação das frações protéicas potencialmente degradáveis. Para tanto, foi realizada a seguinte correção nos perfis de degradação:

$$
\operatorname{Ln}[R(t)-C]=\operatorname{Ln}[B(t)]
$$

em que $R(t)$ corresponde ao resíduo de incubação da proteína bruta da amostra em determinado tempo, $t$; $C$ à fração indegradável; e $B(t)$, ao somatório das frações protéicas potencialmente degradáveis, que restaram após a incubação das amostras por determinado tempo, $t$.

As estimativas médias da degradabilidade ruminal efetiva das frações foram calculadas com base na taxa de passagem hipotética de $0,02 \mathrm{~h}^{-1}$ (AFRC, 1993), para ambas as estações, por meio da expressão:

$$
\operatorname{DEG}\left(B_{i}\right)=\frac{c_{i}}{c_{i}+k}
$$

em que $\operatorname{DEG}\left(B_{i}\right)$ corresponde ao coeficiente de degradabilidade ruminal efetiva da $i$-ésima fração $B_{i}$; $c_{i}$ tem o mesmo significado descrito para as expressões anteriores; e $k$ equivale à taxa de passagem das partículas do alimento.

Os valores referentes ao fracionamento dos compostos nitrogenados foram analisados, considerando o modelo estatístico:

$$
Y_{i j k}=\mu+E_{i}+P_{(i) j}+E_{(i j) k}
$$

em que $Y_{i j k}$ é o valor obtido para a extrusa do $k$-ésimo animal, no $j$-ésimo período, dentro da $i$-ésima estação; ao empregar $\sum n_{i} E_{i}=0$ como restrição às soluções do sistema de equações normais e a restrição paramétrica $\sum_{j} \frac{n_{i j}}{n_{i}} \times P_{i i j}=0, \forall i, \quad \operatorname{com} n_{i}=\sum_{j} n_{i j}, \mu, E_{i}, P_{(i) j}$ e $e_{(i j) k}$ correspondem, respectivamente, à média geral, ao efeito da $i$-ésima estação, ao efeito do $j$-ésimo período dentro da $i$-ésima estação e ao erro aleatório, suposto normal e independentemente distribuído, com média 0 e variância $\sigma^{2}$ (SEARLE, 1971). 


\section{Resultados e Discussão}

O crescimento das plantas forrageiras implica a síntese de parede celular, que ocorre em detrimento das moléculas orgânicas, nutrientes ou não, que participam ativamente dos processos metabólicos; com a deposição de moléculas orgânicas não-nitrogenadas (celulose, hemicelulose, lignina etc), ocorre redução no teor de compostos nitrogenados (MAYNARD et al., 1984; VAN SOEST, 1994). Tal mudança pode ser visualizada na Tabela 1 e na Figura 1. A mudança da EC para a ES acarretou redução significativa do conteúdo protéico (Tabela 2). Assim como para o teor de $\mathrm{PB}$, pode-se observar que os teores das frações $B_{2}$ e $B_{3}$ diminuíram significativamente (Tabela 2). Tal fato representa menor suprimento de isoácidos, exigidos pelos microrganismos do rúmen (RUSSELL et al., 1992), e, concomitantemente, menor escape de proteína verdadeira potencialmente digerível para o intestino, que constitui importante

Tabela 1 - Valores médios ${ }^{1}$ obtidos com o fracionamento dos compostos nitrogenados contidos nas amostras de extrusa

Table 1 - Average values obtained with nitrogenous compounds fractionation contained in the pasture samples

\begin{tabular}{lccccc}
\hline & \multicolumn{2}{c}{$\begin{array}{c}\text { Estação chuvosa } \\
\text { Rainy season }\end{array}$} & & \multicolumn{2}{c}{$\begin{array}{c}\text { Estação seca } \\
\text { Dry season }\end{array}$} \\
\cline { 2 - 3 } \cline { 6 - 6 } Frações $^{2}$ & Período 1 & Período 2 & & Período 1 & Período 2 \\
Fractions $^{2}$ & Period 1 & Period 2 & & Period 1 & Period 2 \\
\hline $\mathrm{A}$ & 5,20 & 7,31 & & 9,64 & 13,19 \\
$\mathrm{~B}_{1}$ & 3,94 & 5,61 & & 14,53 & 7,42 \\
$\mathrm{~B}_{2}$ & 15,99 & 23,25 & & 19,39 & 23,45 \\
$\mathrm{~B}_{3}$ & 55,04 & 37,78 & & 21,33 & 22,31 \\
$\mathrm{C}^{3}$ & 19,83 & 26,05 & & 35,11 & 33,63 \\
$\mathrm{~PB}^{3}, 4$ & 89 & 80 & & 43 & 54 \\
$\mathrm{CP}^{3}, 4$ & & & & &
\end{tabular}

${ }^{1}$ As estimativas das médias provêm de quatro repetições na estação chuvosa e três na estação seca; $2 \%$ da PB;

${ }^{3} \mathrm{~g} \mathrm{~kg}^{-1} \mathrm{MS} ;{ }^{4}$ proteína bruta.

1 The average estimates come from four replications during the rainy season and three in the dry season; $2 \%$ of $C P$.

${ }^{3} \mathrm{~g} \mathrm{~kg}^{-1} \mathrm{DM} ;{ }^{4}$ crude protein.

Tabela 2 - Níveis descritivos dos testes (valores $P$ ) realizados para verificação dos efeitos de estação e períodos dentro das estações chuvosa (P/EC) e seca (P/ES)

Table 2 - Descriptive levels of the tests ( $P$ values) applied to verify the effects of season and periods within the rainy $(P / E C)$ and dry (P/ES) seasons

\begin{tabular}{|c|c|c|c|c|}
\hline $\begin{array}{l}\text { Proporções }{ }^{1} \\
\text { Proportions }^{1}\end{array}$ & $\begin{array}{l}\text { Estação } \\
\text { Season }\end{array}$ & $\mathrm{P} / \mathrm{EC}$ & $\mathrm{P} / \mathrm{ES}$ & $\mathrm{CV}(\%)$ \\
\hline $\begin{array}{l}\mathrm{A} \\
\mathrm{B}_{1} \\
\mathrm{~B}_{2} \\
\mathrm{~B}_{3} \\
\mathrm{C} \\
\left(\mathrm{B}_{3}+\mathrm{C}\right) \\
\left(\mathrm{A}+\mathrm{B}_{1}\right)\end{array}$ & $\begin{array}{c}0,000 \\
0,000 \\
\text { n.s. } \\
0,000 \\
0,000 \\
0,000 \\
0,000\end{array}$ & $\begin{array}{l}0,066 \\
0,286 \\
0,010 \\
0,000 \\
0,020 \\
0,002 \\
0,033\end{array}$ & $\begin{array}{c}0,014 \\
0,002 \\
0,174 \\
\text { n.s. } \\
\text { n.s. } \\
\text { n.s. } \\
0,085\end{array}$ & $\begin{array}{c}17,4 \\
26,8 \\
16,3 \\
11,6 \\
11,6 \\
5,8 \\
13,4\end{array}$ \\
\hline $\begin{array}{l}\text { Teores }^{2} \\
\text { Contents }^{2}\end{array}$ & & & & \\
\hline $\begin{array}{l}\mathrm{PB}^{3} \\
C P^{3} \\
\mathrm{~A} \\
\mathrm{~B}_{1} \\
\mathrm{~B}_{2} \\
\mathrm{~B}_{3} \\
\mathrm{C} \\
\left(\mathrm{B}_{3}+\mathrm{C}\right)\end{array}$ & $\begin{array}{c}\text { n.s. } \\
0,079 \\
0,001 \\
0,000 \\
0,055 \\
0,000\end{array}$ & $\begin{array}{l}0,131 \\
0,228 \\
0,034 \\
0,000 \\
0,079 \\
0,001\end{array}$ & $\begin{array}{c}0,007 \\
0,023 \\
0,071 \\
\text { n.s. } \\
0,171 \\
0,205\end{array}$ & $\begin{array}{l}19,3 \\
23,9 \\
18,0 \\
16,2 \\
12,6 \\
10,8\end{array}$ \\
\hline
\end{tabular}

$1 \%$ da PB; ${ }^{2} \mathrm{~g} \mathrm{~kg}^{-1} \mathrm{MS} ;$ n.s. não-significativo, usado quando $\vec{P}<1 ;{ }^{3}$ proteína bruta.

$1 \%$ of $C P ;^{2} \mathrm{~g} \mathrm{~kg}^{-1} \mathrm{DM} ; n$. . non-significative, used when $\vec{F}<1 ; ;^{3}$ crude protein. 

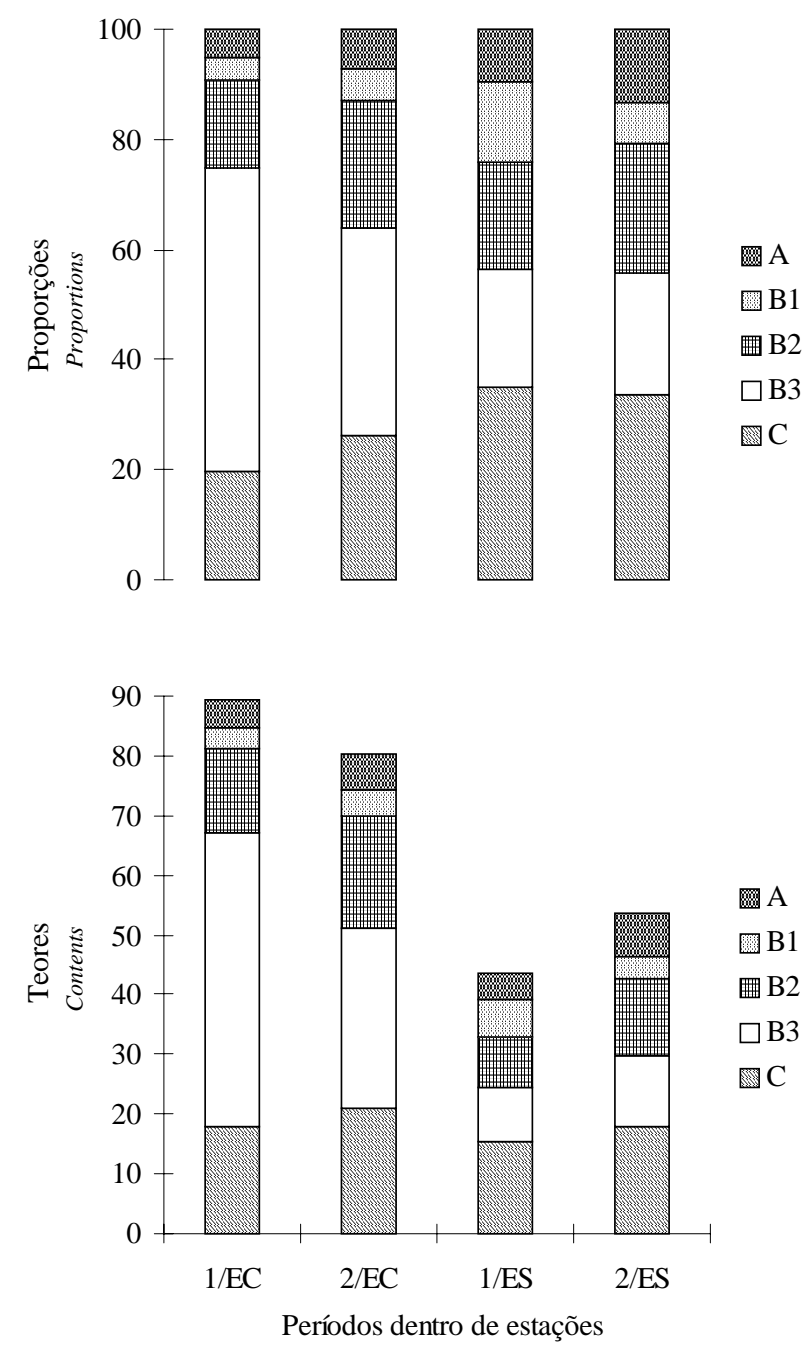

Figura 1 - Variação das proporções (\% PB) e teores $\left(\mathrm{g} \mathrm{kg}^{-1} \mathrm{MS}\right)$ médios das diferentes frações nos respectivos períodos (1 e 2), dentro das estações chuvosa $(E C)$ e seca (ES).

Figure 1 - Variation of the average proportions (\%PB) and contents $\left(\mathrm{g} \mathrm{kg}^{-1} \mathrm{DM}\right)$ of the different fractions in the respective periods (1 and 2) within rainy (EC) and dry (ES) seasons.

fonte de ácidos aminados para o hospedeiro, principalmente a pasto (VAN SOEST, 1994). Vale ressaltar que o conteúdo protéico da pastagem na estação seca esteve abaixo do intervalo crítico de 60 a $80 \mathrm{~g} \mathrm{~PB} \mathrm{~kg}^{-1}$ de matéria seca (MS), o que representa um problema quando se quer manter a eficiência de crescimento microbiano e a capacidade de degradação da fibra (VAN SOEST, 1994). Embora não tenha havido redução significativa no teor da fração $\mathrm{C}$ (Tabela 2), a combinação das frações $\mathrm{B}_{3}$ e $\mathrm{C}$ permite ilustrar, claramente, que a deposição de carboidratos estruturais e de outras substâncias implicou na redução desses valores, como pode ser visto na Figura 1.

No que se refere às proporções $(\%$ da $\mathrm{PB})$ de cada fração em relação à proteína bruta, observou-se que a fração $B_{2}$ foi a única que não sofreu alteração significativa entre as estações (Tabela 2). $\mathrm{O}$ fato de a combinação das frações $\mathrm{A}$ e $\mathrm{B}_{1}$ ter sido diferente entre as estações (Tabela 2) pode ser atribuído à maior proporção que o nitrogênio contido na saliva representou no teor de nitrogênio total da extrusa, durante a ES. Tal condição afetou principalmente as estimativas das frações solúveis, calculadas pela diferença entre a proteína bruta e a proteína insolúvel em ácido tricloroacético e entre esta última e a proteína insolúvel em tampão.

Houve redução significativa na proporção (\% da $\mathrm{PB})$ de $\mathrm{B}_{3}$ e na combinação dos porcentuais de $\mathrm{B}_{3} \mathrm{e}$ $\mathrm{C}$, entre estações, embora tenha ocorrido aumento no porcentual de C (Figura 1, Tabela 2). A fração C é constituída por proteínas associadas à lignina, complexos tânico-protéicos e produtos de Maillard, que são altamente resistentes ao ataque das enzimas de origem microbiana e do hospedeiro; portanto, não pode ser degradada em nível de rúmen e tampouco fornece ácidos aminados para serem absorvidos no intestino delgado (KRISHNAMOORTHY et al., 1982, 1983). A fração C pode ser superestimada pelo processamento (secagem em estufa) das amostras das forrageiras, o que leva à obtenção de resultados menos exatos sobre a degradabilidade e o escape de proteína bruta do rúmen (LONDOÑO-HERNANDÉZ et al., 1998). Esta classe de proteínas, embora haja algumas controvérsias (BRODERICK, 1995), pode ser considerada como indigerível (SNIFFEN et al., 1992; VAN SOEST, 1994; e TOURE e MICHALETDOREAU, 1995). Entre as forrageiras presentes no pasto, o capim-gordura destacou-se por apresentar maior disponibilidade na área experimental (DIOGO, 1995). MALAFAIA et al. (1997) relataram o valor de 24,44 (\% da PB) para a fração C desta forrageira, colhida aos 60 dias após a rebrotação, durante a estação chuvosa na Zona da Mata, Estado de Minas Gerais; este valor é muito próximo ao valor médio da fração C do pasto durante a estação chuvosa (22,94\% da PB), que pode ser obtido a partir dos dados da Tabela 1.

As reduções significativas tanto dos teores ( $\left.\mathrm{g} \mathrm{kg}^{-1} \mathrm{MS}\right)$ como das proporções das frações $\mathrm{B}_{2}$ e $\mathrm{B}_{3}$ (Tabela 2) têm grande importância para a degradação da fibra e a eficiência de crescimento microbiano em animais que estão consumindo dietas com baixo teor de proteína bruta. As taxas de degradação e, 
conseqüentemente, o escape ruminal dessas frações protéicas dependem muito do tipo de alimento empregado na alimentação dos ruminantes (KRISHNAMOORTHY et al., 1983; SNIFFEN et al., 1992). SULTAN et al. (1992) verificaram que o fornecimento de proteína lentamente degradada em nível de rúmen promovia maior aporte de ácidos aminados ao intestino delgado, menores teores de $\mathrm{N}$ amoniacal ruminal e maior conservação do nitrogênio consumido, em relação a outras fontes mais rapidamente degradáveis, por causa da maior reciclagem endógena. POPPI e McLENNAN (1995) verificaram que o aumento do teor de PB do pasto, em função da adubação nitrogenada, não resultava, necessariamente, em maior aporte de ácidos aminados para o intestino delgado e que a síntese de compostos nitrogenados pelos microrganismos era limitada pela disponibilidade de energia. O aumento da disponibilidade de energia, em situações de maior degradabilidade ruminal de compostos nitrogenados, resulta em uma condição mais favorável ao crescimento microbiano e de minimização das perdas nitrogenadas (NOCEK e RUSSELL, 1988; RUSSELL et al., 1992; AFRC, 1993).

As condições dietéticas predominantes no presente estudo apresentaram as seguintes características comparadas àquelas descritas por VAN SOEST (1994): durante a estação seca, o nitrogênio dietético foi insuficiente para atender às exigências tanto dos microrganismos quanto do animal, o que tornaria benéfica a adição de NNP, mas em menor grau que a adição de proteína de lenta degradação ruminal, e deletéria a adição de amido ou açúcares; durante a estação chuvosa, o nível de nitrogênio da dieta foi intermediário, suficiente para os microrganismos, mas insuficiente para atender à exigência total do animal, o que tornaria sem efeito ou deletéria a adição de NNP, e vantajosa a inclusão de amido e de proteína lentamente degradável, o que favorece a utilização do nitrogênio oriundo da reciclagem endógena. Contudo, o impacto econômico de tais práticas precisa ser avaliado.

As taxas de degradação obtidas para as frações protéicas foram muito variáveis. MALAFAIA et al. (1997) usaram enzimas proteolíticas extraídas das bactérias ruminais e obtiveram perfis de degradação que possibilitaram a identificação da fração $B_{1}$ nesses perfis; entretanto, como a utilização do ácido tricloroacético ao final de cada tempo de incubação não foi eficiente para a precipitação da fração $\mathrm{B}_{1}$, no presente estudo, e pelo fato de a soma dos três coeficientes lineares identificados nos perfis ter ultrapassado $100 \%$, foram considerados apenas dois coeficientes lineares, correspondentes às frações $B_{2}$ e $B_{3}$, tendo sido adotada como rotina a não-utilização do ácido ao final da digestão, conforme o procedimento descrito por KRISHNAMOORTHY et al. (1983). Dessa forma, considerou-se que a taxa de degradação desta fração $\left(c_{1}\right)$ tendia para o infinito, ou seja, na escala de tempo adotada, esta taxa de degradação, ou melhor, de solubilização, foi demasiadamente rápida, como pode ser observado na Tabela 3 .

Tabela 3 - Valores médios ${ }^{1}$ das taxas de degradação $\left(c_{i}, \mathrm{~h}^{-1}\right)$ e dos coeficientes de degradabilidade (DEG, valores absolutos) das frações protéicas potencialmente degradáveis $\left(B_{j}\right)$

Table 3 - Average values of the degradation rates $\left(c_{i}, h^{-1}\right)$ and digestibility coefficients (DEG, absolute values) of the potentially degradable protein fractions $\left(B_{i}\right)$

\begin{tabular}{lccccc}
\hline Item & \multicolumn{2}{c}{$\begin{array}{c}\text { Estação chuvosa } \\
\text { Rainy season }\end{array}$} & & \multicolumn{2}{c}{$\begin{array}{c}\text { Estação seca } \\
\text { Dry season }\end{array}$} \\
\cline { 2 - 3 } \cline { 5 - 6 } & $\begin{array}{c}\text { Período 1 } \\
\text { Period 1 }\end{array}$ & $\begin{array}{c}\text { Período 2 } \\
\text { Period 2 }\end{array}$ & & $\begin{array}{c}\text { Período 1 } \\
\text { Period 1 }\end{array}$ & $\begin{array}{c}\text { Período 2 } \\
\text { Period 2 }\end{array}$ \\
\hline $\mathrm{c}_{1}$ & $\infty$ & $\infty$ & & $\infty$ & $\infty$ \\
$\mathrm{c}_{2}$ & $3,218 \pm 2,251$ & $1,635 \pm 1,395$ & & $1,990 \pm 1,576$ & $2,308 \pm 1,388$ \\
$\mathrm{c}_{3}$ & $0,080 \pm 0,017$ & $0,034 \pm 0,008$ & & $0,032 \pm 0,013$ & $0,036 \pm 0,019$ \\
DEG $\left(\mathrm{B}_{1}\right)$ & 1 & 1 & & 1 & 1 \\
DEG $\left(\mathrm{B}_{2}\right)$ & $0,990 \pm 0,007$ & $0,982 \pm 0,010$ & & $0,983 \pm 0,016$ & $0,987 \pm 0,011$ \\
DEG $\left(\mathrm{B}_{3}\right)$ & $0,796 \pm 0,036$ & $0,623 \pm 0,058$ & & $0,595 \pm 0,096$ & $0,616 \pm 0,125$ \\
\hline
\end{tabular}

\footnotetext{
1 Os valores estimados para $c_{2}, c_{3}$, DEG $\left(B_{2}\right)$ e $D E G\left(B_{3}\right)$ provêm de quatro repetições na estação chuvosa e três repetições na estação seca.

1 The estimated values for $c_{2}, c_{3}, D E G\left(B_{2}\right)$ and $D E G\left(B_{3}\right)$ come from four replications in the rainy season and three replications in the dry season.
} 
O Streptomyces griseus é uma bactéria gram-positiva do solo, aeróbia estrita, pertencente ao grupo dos actinomicetos, o qual é constituído por bactérias filamentosas que, em sua maioria, apresentam melhor desenvolvimento em solos bem-drenados e de $\mathrm{pH}$ neutro para alcalino (BROCK et al., 1994). A ação das proteases originárias dessa bactéria apresenta atividade máxima para os estudos de degradação protéica em pH 8 (KRISHNAMOORTHY et al., 1983); daí decorrem as críticas com relação ao uso destas enzimas para obtenção das taxas de degradação (BRODERICK, 1995). Entretanto, CONE et al. (1996) compararam o escape predito pelo método in vitro, usando proteases originárias do S. griseus, e o escape predito a partir do método in situ, e concluíram que o uso das proteases permitia obter, de forma rápida, o porcentual de escape da proteína dietética. Apesar de relatarem que as comparações deveriam ter o método in vivo como referência, a questão da aplicabilidade do método in vitro com a protease do $S$. griseus ainda permanece em aberto, porque os estudos comparativos devem basear-se no método in vivo, por ser este o mais indicado, quando se quer validar as predições com base nos modelos físicos e as interpretações cinéticas obtidas com os modelos matemáticos (KRISHNAMOORTHY et al., 1983). Uma alternativa interessante ao uso das proteases comerciais, considerando os custos de obtenção, seria a utilização das enzimas proteolíticas isoladas das bactérias ruminais, que podem ser obtidas no próprio laboratório (KOHN e ALLEN, 1995; MALAFAIA e VIEIRA, 1997; e MALAFAIA et al., 1997). Contudo, as predições com base neste método devem ser validadas por meio da comparação com os valores obtidos in vivo.

A discrepância nos valores obtidos para as taxas de degradação das demais frações torna não-pertinente, o uso da análise de variância desses dados, sendo, portanto, relatadas apenas as médias e os desviospadrão das taxas de degradação e dos coeficientes de degradabilidade para os diferentes períodos dentro de cada estação do ano (Tabela 3). Deve-se ressaltar também que a literatura é inconsistente no que tange ao efeito do estádio de maturação sobre as taxas de degradação dos nutrientes nas forragens (VIEIRA et al., 1997b). As médias das taxas de degradação para as frações $B_{2}$ e $B_{3}$, de forma geral, foram numericamente maiores que os valores relatados por SNIFFEN et al. (1992) e MALAFAIA et al. (1997). Esta diferença se deve ao vício de identificação dos pontos pertencentes aos diferentes intervalos de linearidade, para degradação de cada fração nos perfis (VIEIRA et al., 1997a) e ao fato de o material empregado nos estudos de degradação corresponder à forragem colhida pelo animal, cujo valor nutritivo predito difere da análise baseada no corte direto das plantas, assim como a composição botânica da pastagem difere da composição botânica da dieta (LIMA et al., 1998). As taxas médias de degradação para a fração $B_{3}$, no presente estudo, foram mais compatíveis, para o mesmo alimento, com as taxas de degradação da FDN relatadas no artigo em conjunto (VIEIRA et al., 2000a), quando comparadas aos valores obtidos por SNIFFEN et al. (1992) e MALAFAIA et al. (1997).

TOURE E MICHALET-DOREAU (1995) avaliaram os perfis de degradação in situ dos compostos nitrogenados solúveis e insolúveis em detergente neutro e obtiveram a determinação de três frações: (1) prontamente solúvel em tampão, (2) solúvel e (3) insolúvel em detergente neutro; as taxas de degradação podem ser obtidas a partir dos perfis isolados das frações solúvel e insolúvel no detergente neutro, sendo a fração indegradável correspondente àquela insolúvel em detergente ácido, o que totalizaria quatro, e não cinco frações, ou seja, o mesmo número obtido com o fracionamento dos carboidratos. BRODERICK (1995) sugeriu quatro, em vez das cinco frações descritas por SNIFFEN et al. (1992), e relatou que estas deveriam ser estimadas para quantificar o NNP, as frações solúvel e insolúvel potencialmente degradáveis e a fração indegradável. Embora tenha apresentado baixo coeficiente de variação, a determinação das frações $A$ e $B_{1}$, de forma conjunta (Tabela 2), reúne compostos nitrogenados de natureza não-protéica e protéica; a solubilidade das últimas não implica necessariamente maior taxa de degradação, portanto, o fracionamento com base em métodos biológicos diretos e na diferenciação do NNP (BRODERICK, 1995) pode resultar em estimativas mais práticas que o fracionamento descrito por LICITRA et al. (1996). Estas estimativas, no entanto, devem ser submetidas a um processo de avaliação análogo ao descrito no presente estudo e no artigo em conjunto (VIEIRA et al., 2000b).

O escape de proteína originária do alimento é principalmente oriundo da fração $B_{3}$, cuja digestibilidade pós-ruminal é da ordem de $80 \%$ (SNIFFEN et al., 1992), porém a quantidade de proteína potencialmente degradável originária do alimento que escapou à degradação ruminal foi muito pequena para o hospedeiro, como pode ser visualizado na Figura 2. 


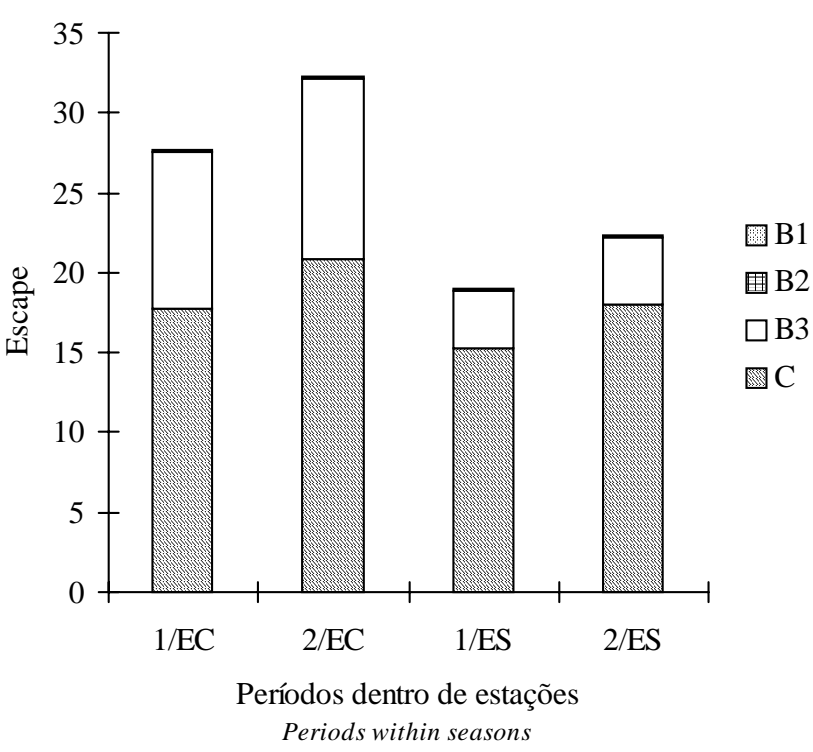

Figura 2 - Escape $\left(\mathrm{g} \mathrm{kg}^{-1} \mathrm{MS}\right)$ esperado para cada fração protéica, nos diferentes períodos (1 e 2) dentro das estações chuvosa (EC) e seca (ES).

Figure 2 - Expected escape $\left(\mathrm{g} \mathrm{kg}^{-1} \mathrm{DM}\right)$ for each protein fraction in the different periods (1 and 2) within wet (EC) and dry (ES) seasons.

\section{Conclusões}

O fracionamento dos compostos nitrogenados é uma metodologia laboriosa e exigente em equipamentos apropriados para determinação do teor de nitrogênio das amostras.

A mudança da estação chuvosa para a estação seca resulta na redução substancial do conteúdo nitrogenado e de suas frações potencialmente degradáveis na forragem colhida pelo animal nesse tipo de pastagem natural.

Há redução da disponibilidade deste nutriente tanto para os microrganismos do rúmen quanto para o hospedeiro, particularmente em virtude do aumento na proporção da fração $\mathrm{C}$ em relação à proteína bruta. As frações $B_{1}$ e $B_{2}$, em ambas as estações, são amplamente degradadas no rúmen.

\section{Agradecimento}

Ao Conselho Nacional de Desenvolvimento Científico e Tecnológico (CNPq), pelas bolsas de estudo e pelo suporte financeiro ao projeto.

\section{Referências Bibliográficas}

AGRICULTURAL AND FOOD RESEARCH COUNCIL AFRC. 1993. Energy and protein requirements of ruminants. Cambridge: CAB International. 159p.

BRODERICK (1995) sugeriu que a taxa de passagem de partículas fosse substituída pela taxa de diluição ou taxa de passagem de líquido para a estimativa da degradabilidade das frações solúveis. Contudo, no presente estudo, esta correção teria efeito nulo para a fração $\mathrm{B}_{1}$ : ao aplicar $\operatorname{Lim}_{c i \rightarrow \infty} \frac{c_{i}}{c_{i}+k}$, sempre que $\forall c_{i} \rightarrow \infty$, esta expressão tende a uma indeterminação do tipo $\infty / \infty$; assim, aplicando a regra de L'Hospital, tem-se que $\frac{\mathrm{dc}_{\mathrm{i}} / \mathrm{dc}_{\mathrm{i}}}{\mathrm{d}\left(\mathrm{c}_{\mathrm{i}}+\mathrm{k}\right) / \mathrm{dc} \mathrm{c}_{\mathrm{i}}}=\frac{1}{1+0}=1$. Considerando-se que a taxa de passagem de líquido está em torno de três vezes a taxa de passagem de sólidos (UDÉN et al., 1982; VAN SOEST, 1994), as degradabilidades efetivas corrigidas para a fração $\mathrm{B}_{2}$, obtidas ao multiplicar as frações pelos respectivos coeficientes de degradabilidade calculados de acordo com a equação (3), a saber: 0,$9817 ; 0,9646 ; 0,9707$; e 0,9747 , resultariam no escape de, aproximadamente, 0,26; 0,66; 0,24; e $0,32 \mathrm{~g} \mathrm{~kg}^{-1} \mathrm{MS}$ consumida, ou seja, um aporte desprezível desta fração do nitrogênio dietético para os intestinos. Contudo, $\mathrm{B}_{2}$ é interessante fonte de isoácidos para os microrganismos fibrolíticos nesta situação, uma vez que foi quase totalmente degradada no rúmen (Tabela 3; Figura 2).
BROCK, T.D., MADIGAN, M.T., MARTINKO, J.M. et al. 1994. Biology of Microorganisms. 7 ed. Englewood Cliffs: Prentice-Hall International. 909p.

BRODERICK, G.A. Methodology for the determining ruminal degradability of feed proteins In: SIMPÓSIO INTERNACIONAL SOBRE EXIGÊNCIAS NUTRICIONAIS DE RUMINANTES, Viçosa, 1995. Anais... Viçosa: DZO, 1995. p.139-176.

CONE, J.W., VAN GELDER, A.H., STEG, A. et al. 1996. Prediction of in situ rumen escape protein from in vitro incubation with protease from Streptomyces griseus. J. Sci. Food Agric., 72:120-126.

DIOGO, J.M.S. Composição botânica e valor nutritivo da dieta selecionada por novilhos em pastagem natural de ViçosaMG. Viçosa, MG: UFV, 1995. 108p. Tese (Doutorado em Zootecnia) - Universidade Federal de Viçosa, 1995.

FOX, D.G., SNIFFEN, C.J., O'CONNOR, J.D. et al. 1992. A net carbohydrate and protein system for evaluating cattle diets III. Cattle requirements and diet adequacy. J. Anim. Sci., 70(12):3578-3596.

LONDOÑO-HERNANDÉZ, F.I., VIEIRA, R.A.M., SANCHEZ, sobre o desaparecimento ruminal e as digestibilidades intestinal e total da proteína de duas gramíneas. R. Bras. Zootec., 27(4):783-789.

KOHN, R.A., ALLEN, M.S. 1995. In vitro protein degradation of feeds using concentrated enzymes extracted from rumen contents. Anim. Feed Sci. Technol., 52:15-28. L.M.B. et al. 1998. Efeito do processamento da amostra 
888 Rev. bras. zootec.

KRISHNAMOORTHY, U., MUSCATO, T.V., SNIFFEN, C.J. et al. 1982. Nitrogen fractions in selected feedstuffs. J. Dairy Sci., 65(2):217-225.

KRISHNAMOORTHY, U., SNIFFEN, C.J., STERN, M.D. et al. 1983. Evaluation of a mathematical model of rumen digestion and an in vitro simulation of rumen proteolysis to estimate the rumen-undegraded nitrogen content of feedstuffs. Brit. J. Nutr., 50(2):555-568.

LENG, R.A. 1993. Quantitative ruminant nutrition: a green science. Austr. J. Agric. Res., 44(1):363-380.

LICITRA, G., HERNANDEZ, T.M., VAN SOEST, P.J. 1996. Standardization of procedures for nitrogen fractionation of ruminant feeds. Anim. Feed Sci. Technol., 57:347-358.

LIMA, J.A., NASCIMENTO JÚNIOR, D., PEREIRA, J.C. et al. 1998. Seletividade por bovinos em pastagem natural. 1 . Composição botânica. R. Bras. Zootec., 27(3):434-443.

MADSEN, J., HVELPLUND, T. 1994. Prediction of in situ protein degradability in the rumen: results of an european ringtest. Lvstck. Prod. Sci., 39(1):201-212.

MALAFAIA, P.A.M., VIEIRA, R.A.M. Técnicas de determinação e avaliação dos compostos nitrogenados em alimentos para ruminantes In: SIMPÓSIO INTERNACIONAL DE DIGESTIBILIDADE EM RUMINANTES, Lavras, 1997. Anais...Lavras: FAEPE, 1997. p.29-54.

MALAFAIA, P.A.M., VALADARES FILHO, S.C., VIEIRA, R.A.M. et al. 1997. Determinação e cinética ruminal das frações protéicas de alguns alimentos para ruminantes. R. Bras. Zootec., 26(6):1243-1251.

MAYNARD, L.A., LOOSLI, J.K., HINTZ, H.F. et al. 1984. Nutrição animal. 3.ed. Rio de Janeiro: Livraria Freitas Bastos S.A. 726p.

MINSON, D.J., STOBBS, T.H., HEGARTY, M.P. et al. 1976. Measuring the nutritive value of pasture plants. In: SHAW, N.H., BRYAN, W.W. (Eds.) Tropical pasture research. principles and methods. Hurley: CAB International. p.308-337.

NOCEK, J.E. 1988. In situ and other methods to estimate ruminal protein and energy digestibility: a review. J. Dairy Sci., 71(8):2051-2069.

NOCEK, J.E., RUSSELL, J.B. 1988. Protein and energy as an integrated system. Relationship of ruminal protein and carbohydrate availability to microbial synthesis and milk production. J. Dairy Sci., 71(8):2070-2107.

NATIONAL RESEARCH COUNCIL - NRC. 1996. Nutrients requirements of beef cattle. 7.ed. Washington, DC: National Academy Press. 242p.

O'CONNOR, J.D., SNIFFEN, C.J., FOX, D.G. et al. 1993. A net carbohydrate and protein system for evaluating cattle diets: IV. Predicting amino acid adequacy. J. Anim. Sci., 71(5):1298-1311.

POPPI, D.P., McLENNAN, S.R. 1995. Protein and energy utilization by ruminants at pasture. J. Anim. Sci., 73(1):278-290.

REZENDE, S.B, REZENDE, M., GALLOWAY, H.M. 1972. Crono-toposequência de solos em Viçosa, Minas Gerais. R. Ceres, 19(103):167-181.
RUSSELL, J.B., O'CONNOR, J.D., FOX, D.G. et al. 1992. A net carbohydrate and protein system for evaluating cattle diets: I. Ruminal fermentation. J. Anim. Sci., 70(12):3551-3561.

SEARLE, S.R. 1971. Linear models. New York: John Wiley \& Sons. 532p.

SNIFFEN, C.J., O'CONNOR, J.D., VAN SOEST, P.J. et al. 1992. A net carbohydrate and protein system for evaluating cattle diets: II. Carbohydrate and protein availability. $J$. Anim. Sci., 70(12):3562-3577.

SULTAN, J.I., FIRKINS, J.L., WEISS, W.P. et al. 1992. Effects of energy level and protein source on nitrogen kinetics in steers fed wheat straw-based diets. J. Anim. Sci., 70(12):39163921.

TOURE, S.F., MICHALET-DOREAU, B. 1995. Nitrogen partition in cell structures of tropical browse plants compared with temperate forages: influence on their in situ degradation pattern. Anim. Feed Sci. Technol., 51:65-72.

UDÉN, P., ROUNSAVILLE, T.R., WIGGANS, G.R. et al. 1982. The measurement of liquid and solid digesta retention in ruminants, equines and rabits given timothy (Phleum pratense) hay. Br. J. Nutr., 48(2):329-339.

VAN SOEST, P.J., ROBERTSON, J.B., LEWIS, B.A. 1991. Methods for dietary fiber, neutral detergent fiber, and nonstarch polyssacharides in relation to animal nutrition. $J$. Dairy Sci., 74(10):3583-3597.

VAN SOEST, P.J. 1994. Nutritional ecology of the ruminant. 2.ed. Ithaca: Cornell University Press. 476p.

VIEIRA, R.A.M., PEREIRA, J.C., MALAFAIA, P.A.M. et al. 1997a. Application of non-linear models in the description of in situ degradation profiles of the elephant-grass (Pennisetum purpureum, Schum.). Anim. Feed Sci. Technol., 66:197-210.

VIEIRA, R.A.M., PEREIRA, J.C., MALAFAIA, P.A.M. et al. 1997b. The influence of elephant-grass (Pennisetum purpureum Schum., Mineiro variety) growth on the nutrient kinetics in the rumen. Anim. Feed Sci. Technol., 67:151-161.

VIEIRA, R.A.M., PEREIRA, J.C., MALAFAIA, P.A.M. et al. 2000a. Fracionamento dos carboidratos e cinética de degradação in vitro da fibra em detergente neutro da extrusa de bovinos a pasto. Rev. bras. zootec., 29(3):889-897.

VIEIRA, R.A.M., PEREIRA, J.C., MALAFAIA, P.A.M. et al. 2000b. Simulação da dinâmica de nutrientes no trato gastrintestinal: aplicação e validação de um modelo matemático para bovinos a pasto. Rev. bras. zootec., 29(3):898-909.

Recebido em: 09/09/98

Aceito em: 25/10/99 